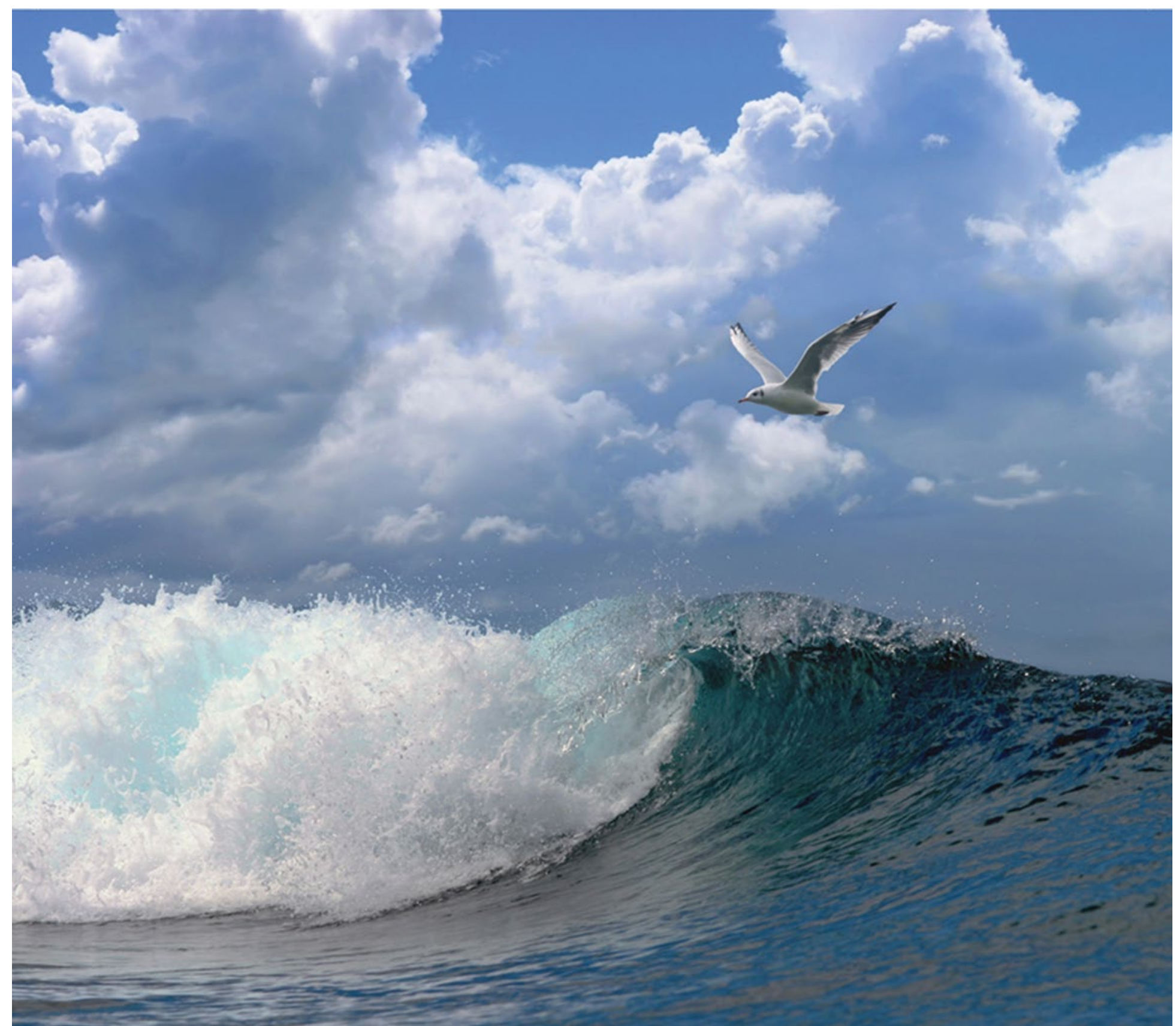

\title{
Experimentele luchtdruk wing als vangsttechniek voor platvis
}




\section{Experimentele Luchtdruk wing als vangsttechniek voor platvis}

Auteur: Pieke Molenaar

Publicatie datum: December 2019 
Pieke Molenaar, Experimentele Luchtdruk wing als vangsttechniek voor platvis; Wageningen Marine Research rapport C132/19, 13 blz.

Opdrachtgever: Visserij-Innovatiecentrum zuidwest Nederland

T.a.v.: dhr. J.A. van Nieuwenhuijzen

Meester Snijderweg 7

3251 LJ Stellendam

Projectnummer: 4316100161.

Dit rapport is gratis te downloaden van https://doi.org/10.18174/509631

Wageningen Marine Research verstrekt geen gedrukte exemplaren van rapporten.

\section{(C) 2016 Wageningen Marine Research}

Wageningen Marine Research, onderdeel van Stichting DLO.

KvK nr. 09098104,

IMARES BTW nr. NL 8113.83.696.B16

Code BIC/SWIFT address: RABONL2U

IBAN code: NL 73 RABO 0373599285
De Directie van Wageningen Marine Research is niet aansprakelijk voor gevolgschade, noch voor schade welke voortvloeit uit toepassingen van de resultaten van werkzaamheden of andere gegevens verkregen van IMARES; opdrachtgever vrijwaart IMARES van aanspraken van derden in verband met deze toepassing.

Dit rapport is vervaardigd op verzoek van de opdrachtgever hierboven aangegeven en is zijn eigendom. Niets uit dit rapport mag weergegeven en/of gepubliceerd worden, gefotokopieerd of op enige andere manier gebruikt worden zonder schriftelijke toestemming van de opdrachtgever. 


\section{Inhoud}

$\begin{array}{lr}\text { Samenvatting } & 4\end{array}$

$1 \quad$ Inleiding $\quad \mathbf{5}$

2 Methoden $\quad 6$

$\begin{array}{lll}2.1 & \text { Ethische gronden } & 6\end{array}$

2.2 Experimentele opzet $\quad 6$

$\begin{array}{lll}2.2 .1 & \text { Bassin } & 6\end{array}$

2.2.2 Experimentele opstelling $\quad 6$

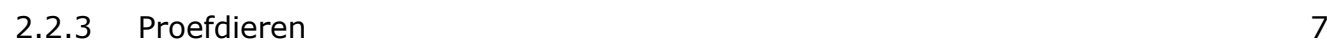

$\begin{array}{lll}2.3 & \text { Experimenten zonder vis } & 8\end{array}$

2.4 Experiment met vis $\quad 8$

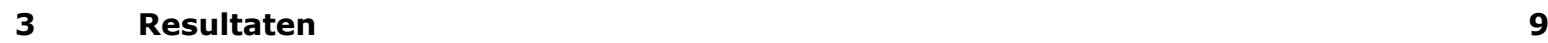

$\begin{array}{lll}3.1 & \text { Experimenten zonder vis } & 9\end{array}$

$\begin{array}{ll}3.2 & \text { Experimenten met vis }\end{array}$

4 Conclusies $r$

$\begin{array}{llr}5 & \text { Kwaliteitsborging } & 11\end{array}$

$\begin{array}{lr}\text { Verantwoording } & 12\end{array}$ 


\section{Samenvatting}

Met het volledig verbieden van de pulstechniek wordt er binnen de Nederlandse visserijsector gekeken naar een alternatief voor elektrische (puls) of mechanische (wekker kettingen) stimulering om platvis te vangen. Een mogelijkheid werd gezien in het stimuleren van platvis door middel van perslucht. Om de werking en effectiviteit van dit idee te testen is door texelaar Piet Standaard een aqua dynamische luchtdruk wing ontwikkeld die de lucht richting de grond blaast. Om de werking van het innovatieve ontwerp te testen is er gekozen om een eerste experiment te doen met een schaalmodel in het Visserij Innovatie Centrum zuidwest Nederland (VIC). De uitgevoerde proeven met tong en schol laten zien dat in deze opstelling een zeer beperkt aantal vissen reageert op de luchtbellen. Ook dient de opstelling zeer dicht boven de bodem langs te gaan $(8 \mathrm{~cm})$ om effectief de luchtbellen onder snelheid de bodem te laten raken. De huidige opstelling lijkt nog geen alternatief voor wekkerkettingen of puls te bieden gezien de beperkte effectiviteit waarmee tong en schol gestimuleerd worden om de bodem te verlaten. Verder ontwikkeling en verbetering is noodzakelijk om tot een rendabele visserijmethode te komen. 


\section{$1 \quad$ Inleiding}

Met het volledig verbieden van de pulstechniek wordt er binnen de Nederlandse visserijsector gekeken naar een alternatief voor elektrische (puls) of mechanische (wekker kettingen) stimulering om platvis te vangen. Een mogelijkheid werd gezien in het stimuleren van platvis door middel van perslucht. Het idee is om platvissen met luchtbellen te prikkelen zodat zij opzwemmen van- of uit de zeebodem en dan met een sleepnet gevangen kunnen worden. Voor de visserij met wekkerkettingen is de ontwikkeling van een alternatieve visserijtechniek die tot minder brandstofgebruik leidt gewenst. Om de werking en effectiviteit van dit idee te testen is door Piet Standaard een prototype van een aqua dynamische-luchtdruk wing ontwikkeld die tijdens het vissen lucht richting de zeebodem blaast. Met dit prototype kunnen testen gedaan worden onder gecontroleerde omstandigheden.

Vooraf was onbekend of platvissen die zich op of in de zeebodem bevinden met luchtbellen dusdanig geprikkeld kunnen worden dat zij loskomen van de bodem zodat zij vervolgens met een sleepnet gevangen kunnen worden. Ook was niet bekend welke verschillen in 'prikkelbaarheid met lucht' bestaan tussen vissoorten en tussen vissen van verschillende grootte binnen vissoorten en hoe deze verschillen zijn gerelateerd aan technische instelling van het vistuig op basis van luchtbellen. Kennis van dergelijke verschillen is echter van belang voor de ontwikkeling van een vistuig waarbij perslucht gebruikt wordt om de vissen te simuleren om de bodem te verlaten.

Om de werking van het innovatieve ontwerp te testen is er gekozen om een eerste experiment te doen met een schaalmodel in het Visserij Innovatie Centrum zuidwest Nederland (VIC), gevestigd bij de visserijhaven van Stellendam.

Het doel van het experiment was:

- Het vaststellen van de mogelijkheid schol en tong met een aqua dynamische luchtdruk wing dusdanig met luchtbellen te prikkelen dat zij te vangen zijn met een sleepnet.

- Het vaststellen het effect van diverse technische instellingen van het luchtdruk Wing-vistuig op de mate waarin schol en tong geprikkeld worden. 


\section{Methoden}

\subsection{Ethische gronden}

De experimenten zijn in overeenkomst met de Nederlandse Wet op de dierproeven (WOD) uitgevoerd. Het project waaronder het experiment valt, is goedgekeurd door de Centrale Commissie Dierproeven (Project 2017.D-0012). Het experiment is goedgekeurd door de Instantie voor Dierenwelzijn (IvD) van Wageningen Research (Experiment 2017.D-0012.005).

\subsection{Experimentele opzet}

\subsubsection{Bassin}

In het VIC bevindt zich een en bassin van 32,8x3,2x2 m ( $\mathrm{LxBxH}$ ) gevuld met $175 \mathrm{~m}^{3}$ zeewater. Hier het bassin is de bodem bedekt met een laag van $25 \mathrm{~cm}$ gekalibreerd filterzand, hierdoor is de waterdiepte tot op de zandlaag $170 \mathrm{~cm}$. Tijdens de experimenten was de watertemperatuur $15.2^{\circ} \mathrm{C}$ met een saliniteit van $23 \mathrm{~g} \cdot \mathrm{L}^{-1}$.

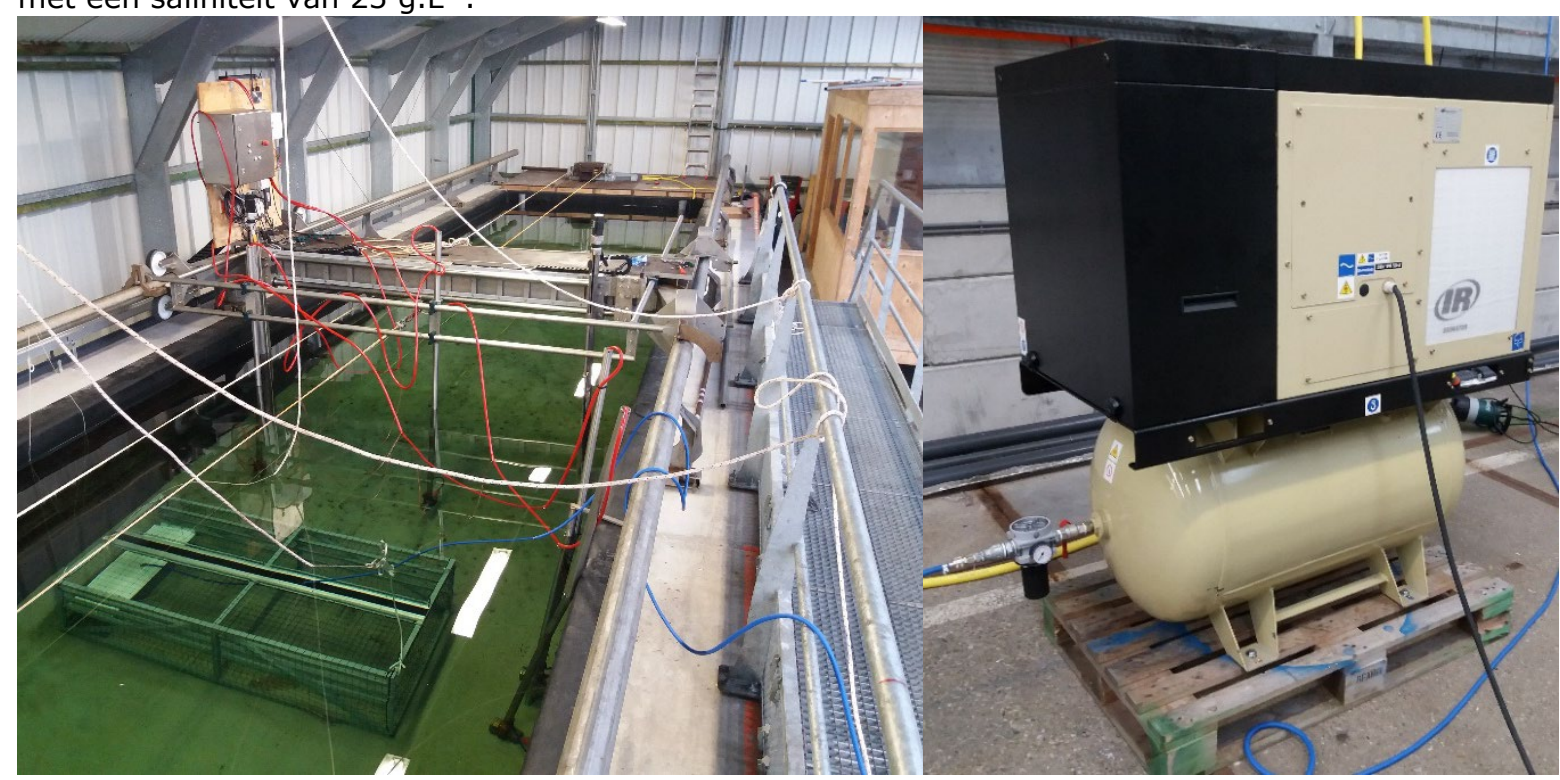

Figuur 1. Het zoutwaterbassin in het VIC met daarin de experimentele opstelling en naast het bassin de compressor.

\subsubsection{Experimentele opstelling}

Voor het experiment is er gebruik gemaakt van speciale kooi ( $2 \times 0.9 \times 0.5 \mathrm{~m}, \mathrm{LxB} \times \mathrm{H})$ om de vissen in een beperkt gebied onder de luchtdruk Wing te houden. Rondom de RVS kooi is $80 \mathrm{~mm}$ netwerk gespannen waarvan de mazen in vierkante positie (T45) gezet zijn.

De luchtdruk Wing heeft een afmeting van $90 \times 30 \mathrm{~cm}$ en heeft daarmee eenzelfde breedte als de kooi. Onder de wing zijn nozzles aangebracht welke op een afstand van $10 \mathrm{~cm}$ uit elkaar geplaatst zijn. Er zijn nozzles $1 \mathrm{~mm}$ en $1.5 \mathrm{~mm}$ beschikbaar voor de proeven. De wing was verbonden met een compressor (Figuur 1) voor het genereren van luchtruk op de bodem van de tank. Achter de wing was een klein fijnmazig netje ( $20 \mathrm{~mm}$ maaswijdte) met een kettinkje bevestigd, dit om eventuele opspringende vissen te vangen. Echter bleek na de eerste testen dat dit netje hier niet voor geschikt was in deze opstelling, onder snelheid kwam het netwerk omhoog en hing recht achter de wing waardoor het vervolgens over de vis heen ging. 
De wing heeft aan beide zijkanten rollers die hem in positie houden en waarmee hij door de gleuven in de zijkant van de kooi voortgetrokken kan worden. Om met de hoogte van de wing boven de bodem te kunnen experimenteren zijn er 3 gleuven aangebracht op 30, 20 en $8 \mathrm{~cm}$ boven de bodem (zie Figuur 33). De luchtdruk kan gereguleerd worden van 2 tot 8 bar.

Op de kooi waren 4 onderwatercamera's gericht waarmee de reactie van in de kooi geplaatste vissen op de voorgetrokken luchtdruk Wing tijdens de proeven werden vastgelegd uit verschillende hoeken. In de controlekamer van het VIC werden de beelden teruggekeken na het experiment om de effecten de beoordelen. De beelden zijn gearchiveerd voor toekomstig gebruik.
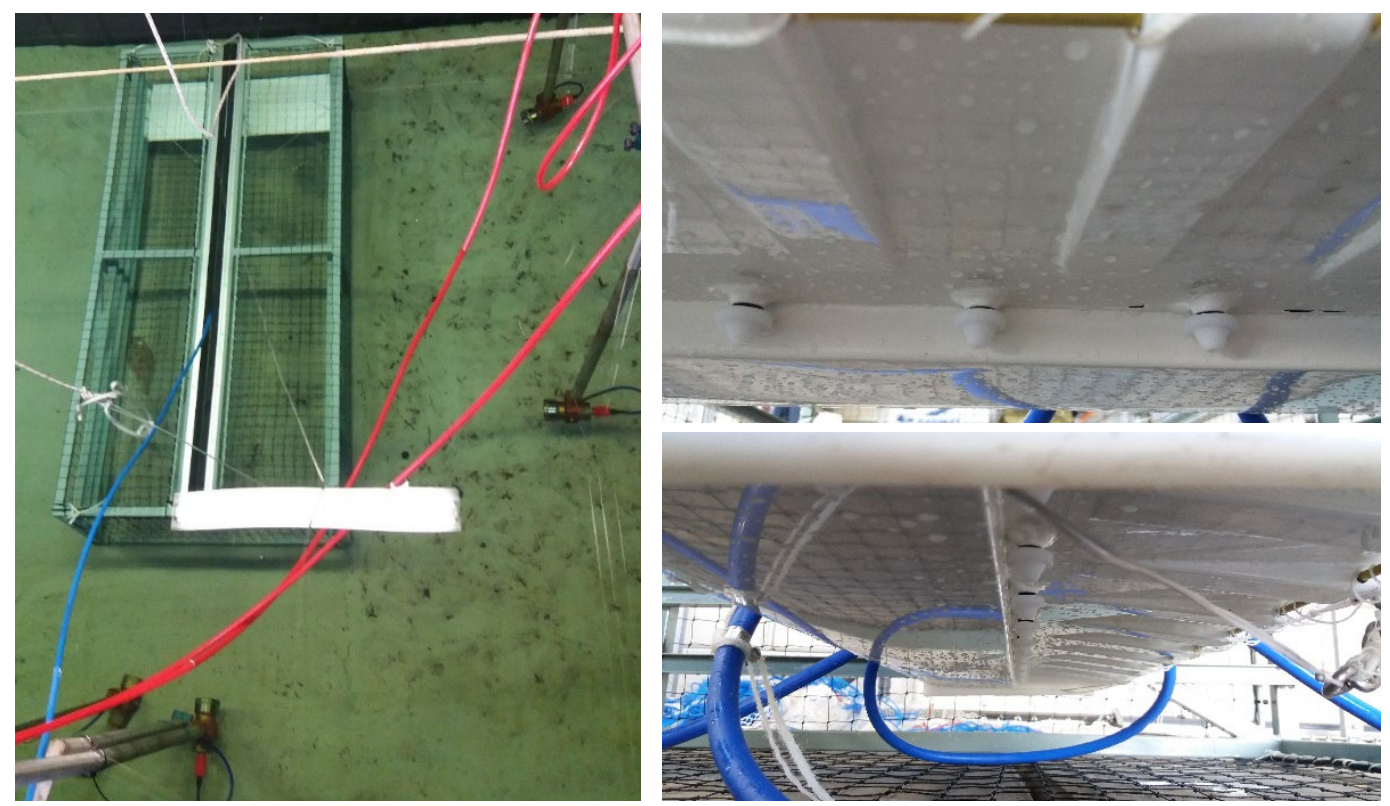

Figuur 2. Links de testopstelling met kooi met daarin tong en schol. Bovenin de kooi is het witte vleugelprofiel (wing) te zien waaronder zich de nozzles voor de luchtbellen bevinden. De wing kan handmatig voortgetrokken worden aan de blauwe luchtslang. Bij de onderzijde en zijkant van de kooi zijn twee camera's geplaatst om het effect van luchtbellen op de vissen waar te nemen. Rechts boven de onderzijde van de wing gezien van achteren. Rechts onder het onderaanzicht van de wing vanaf de zijkant gezien, duidelijk zichtbaar zijn de nozzles in het midden van de wing die luchtbellen creëren om vis te prikkelen.

\subsubsection{Proefdieren}

De experimenten met de luchtdruk Wing zijn uitgevoerd met ondermaatse schol $(<27 \mathrm{~cm})$ en maatse tong $(>24 \mathrm{~cm})$, dit omdat schol en tong de voornaamste doelsoorten zijn van de puls en boomkorvisserij. De vissen zijn twee weken voor de uitvoering van experiment verzameld door een met pulstuigen uitgerust commercieel vissersschip. Tijdens het verwerken van de vangst zijn de vissen in de best beschikbare conditie geselecteerd en aan boord opgeslagen in een beluchte en een met zeewater doorstroomde $600 \mathrm{I}$ tub. Bij aankomst in de haven van Stellendam zijn de vissen in de tubs naar het VIC vervoerd en gehuisvest in de speciaal daarvoor ingerichte bakken. Deze bakken zijn voorzien van grof zand, beluchting en worden doorstroomd met water uit het testbassin, op deze manier wennen de vissen aan de huisvestingsomstandigheden. Tijdens het verblijf in het VIC zijn de vissen gevoerd met zagers.

Voor dit experiment zijn de vissen door de dierverzorger en onderzoeker van de opslagtubs overgebracht naar de kooi in het bassin. Na elk experiment zijn de vissen visueel geïnspecteerd op eventuele beschadigingen terwijl de kooi op de bodem bleef staan. Indien beschadigingen waargenomen werden is de betreffende vis uit de experimentele opstelling verwijderd, dit is echter niet voorgekomen. Na drie experimenten met dezelfde vissen zijn deze weer overgezet in de houderij faciliteiten. Na afloop van de experimenten zijn de vissen levend vrijgelaten in hun natuurlijke habitat. 


\subsection{Experimenten zonder vis}

Op basis van een serie experimenten zonder vis is vastgesteld dat een luchtdruk uit de wing van minimaal 5 bar nodig is om met luchtbellen op werveling van zand van de bodem te bewerkstelligen. De experimenten met vissen zijn daarom met een luchtdruk van 5 tot 8 bar uitgevoerd.

\subsection{Experiment met vis}

De eerste experimenten met vissen werden uitgevoerd met de wing op $20 \mathrm{~cm}$ boven de bodem, een luchtdruk van 5 en 7 bar en met 9 tongen in de kooi. Experiment 3, 4, en 5 werd uitgevoerd met 6 tongen en 4 schollen waarbij de wing $8 \mathrm{~cm}$ boven de bodem langs ging in combinatie met en een luchtdruk van 8 bar en grotere nozzles. In experiment 3 werd de wing met $1 \mathrm{~m} / \mathrm{s}$ voorgetrokken, bij 4 en 5 was dit $0.5 \mathrm{~m} / \mathrm{s}$. Een overzicht van de experimenten wordt gegeven in Tabel 1 . De vissen zijn op voorwaarde dat ze in goede conditie waren maximaal 3x blootgesteld aan luchtbellen, waarbij tussen elke blootstelling een pauze van minimaal 30 minuten is gehanteerd. Na een experiment is eerst minimaal 30 minuten gewacht voordat een volgende experiment is uitgevoerd met de zelfde vissen. Bij nieuwe vissen werd ook 30 minuten gewacht om ze aan de nieuwe omgeving te laten wennen.

Tabel 1. Specificaties van de experimenten met vis met de luchtdruk Wing:, aantal experimenten, blootstellingsnummer van de groep vissen, aantal vissen, hoogte van de wing boven de bodem, diameter van de nozzles, snelheid en de druk bij de uitgang van de compressor.

\begin{tabular}{ccccccccc}
$\begin{array}{c}\text { Experi } \\
\text { ment } \\
\mathrm{nr}\end{array}$ & $\begin{array}{c}\text { Bloot- } \\
\text { stelling } \\
\mathrm{nr}\end{array}$ & $\begin{array}{c}\text { Aantal } \\
\text { schollen }\end{array}$ & $\begin{array}{c}\text { Aantal } \\
\text { tongen }\end{array}$ & $\begin{array}{c}\text { Acclimat- } \\
\text { isatie } \\
(\mathrm{min})\end{array}$ & $\begin{array}{c}\text { Hoogte wing } \\
\text { boven bodem } \\
(\mathrm{cm})\end{array}$ & $\begin{array}{c}\text { Diameter } \\
\text { luchtgaten } \\
\text { nozzle }(\mathrm{mm})\end{array}$ & $\begin{array}{c}\text { Druk } \\
(\mathrm{bar})\end{array}$ & $\begin{array}{c}\text { Snelheid } \\
(\mathrm{m} / \mathrm{s})\end{array}$ \\
\hline 1 & 1 & - & 9 & 32 & 20 & 1.5 & 5 & 1.5 \\
\hline 2 & 2 & - & 9 & 31 & 20 & 1.5 & 7 & 1.5 \\
\hline 3 & 1 & 4 & 6 & 34 & 8 & 2 & 8 & 1 \\
\hline 4 & 2 & 4 & 6 & 79 & 8 & 2 & 8 & 0.5 \\
\hline 5 & 3 & 4 & 6 & 38 & 8 & 0.5 \\
\hline
\end{tabular}

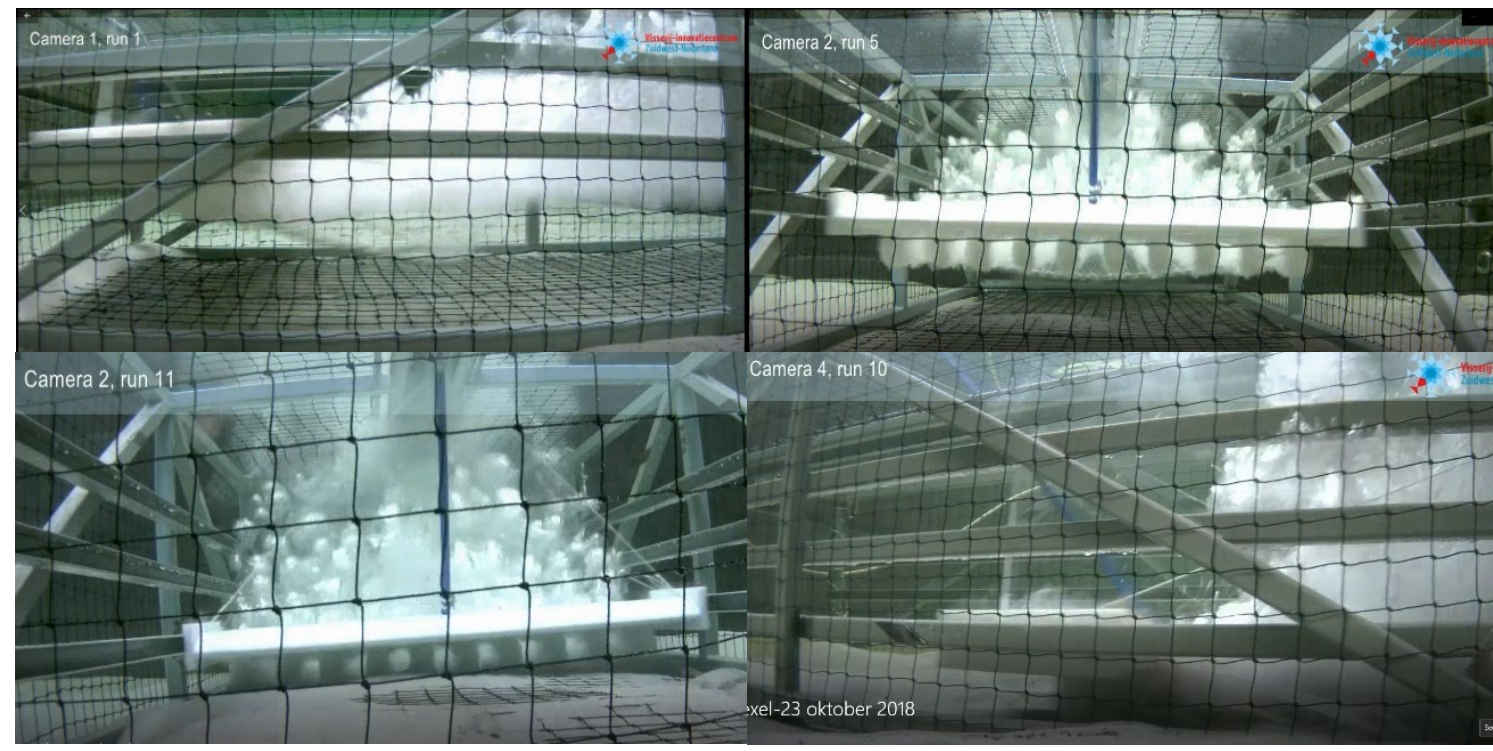

Figuur 3. Boven het voor en zijaanzicht van de luchtdruk Wing waarbij de wing $20 \mathrm{~cm}$ boven de bodem voortgetrokken wordt. Op de beelden is zichtbaar dat de luchtbellen de bodem niet halen. Onder het voor en zijaanzicht van de luchtdruk Wing waarbij de wing $8 \mathrm{~cm}$ boven de bodem voortgetrokken wordt. Op deze hoogte raken de luchtbellen de bodem. 


\section{Resultaten}

\subsection{Experimenten zonder vis}

Voordat er vissen in de experimentele opstelling gezet werden is er eerst gekeken bij welke afstand van de luchtdruk Wing tot de bodem de luchtbellen de bodem raken. De resultaten zijn weergegeven in Tabel 2 en zichtbaar in Figuur 3. Hierbij kwam naar voren dat bij een hoogte van 30 en 20 centimeter de zandkorrels zich niet verplaatsen (boven).

Tabel 2. Resultaten van test zonder vissen om effectieve hoogte van wing met luchtbellen boven bodem te bepalen.

\begin{tabular}{cl} 
Hoogte wing van bodem $(\mathbf{c m})$ & \multicolumn{1}{c}{ Effect } \\
\hline $\mathbf{3 0}$ & Geen verplaatsing van zandkorrels op bodem \\
\hline $\mathbf{2 0}$ & $\begin{array}{l}\text { Geen verplaatsing zandkorrels. Bij een wing op } \\
\text { snelheid komen luchtbellen minder diep. }\end{array}$ \\
\hline $\mathbf{8}$ & Luchtbellen raken bodem \\
\hline
\end{tabular}

\subsection{Experimenten met vis}

In experiment 1 en 2 met tong waarbij de wing $20 \mathrm{~cm}$ boven de bodem langs ging werd geen enkele reactie van de vissen waargenomen (Tabel 3, Figuur 3 Boven). Omdat deze hoogte geen effect op de vissen had, is de opstelling aangepast waarbij de luchtdruk Wing op $8 \mathrm{~cm}$ boven de bodem getest kon worden (onder). In de vervolg experimenten 3, 4 en 5 met de wing op $8 \mathrm{~cm}$ hoogte werden opnieuw geen of zeer beperkte reacties van de vissen in de kooi waargenomen (Tabel 3)

Tabel 3. Observaties per experiment van de effecten van luchtdruk Wing op vissen en experimentele opstelling.

\begin{tabular}{cl} 
Experiment nr. & Bevindingen \\
\hline 1 & $\begin{array}{l}\text { Twee tongen lagen in het netje achter de wing voordat het experiment begon, verder geen } \\
\text { reactie overige vis. }\end{array}$ \\
\hline 2 & $\begin{array}{l}\text { Geen beweging tong, bellen lijken } 3 \mathrm{~cm} \text { dieper te komen maar komen onder snelheid niet bij } \\
\text { bodem. Luchtbellen komen ongeveer } 12 \mathrm{~cm} \text { onder vleugel, tot } 8 \mathrm{~cm} \text { boven bodem geen bubbels. }\end{array}$ \\
\hline 3 & $\begin{array}{l}\text { Geen reactie vissen. Een tong heeft zich vast gezwommen in de mazen van de kooi. } \\
\text { Het lijkt erop dat er } 3 \text { vissen in het netje achter de wing gezeten hebben. Zicht moeilijk door } \\
\text { opwellend zand op het moment dat de vleugen niet vooruit getrokken wordt. Onduidelijk of } \\
\text { ophalen dan de kooi liggen er } 3 \text { tongen onder de eindpositie van de vleugel. }\end{array}$ \\
\hline 5 & \begin{tabular}{l} 
Een tong zwemt $20 \mathrm{~cm}$ vooruit, verder geen reactie overige vissen. \\
\hline
\end{tabular}
\end{tabular}




\section{Conclusies}

Platvis ligt van nature in of op de bodem, om gevangen te worden dient te platvis gestimuleerd te worden om los van de bodem te komen zodat deze over de grondpees van een sleepnet gaan en daardoor gevangen worden in het net. Indien de platvis op of in de bodem blijft liggen gaat de grondpees over de vissen heen en worden ze niet gevangen. Om de platvis en met name tong los van de zeebodem te krijgen worden in een traditioneel boomkor wekkerkettingen gebruikt, en met de puls elektrische stroomstootjes. In dit experiment is geprobeerd om met luchtbellen onder een vleugelprofiel boven de bodem de vis te stimuleren om de bodem te verlaten. Echter, laten de proeven zien dat in deze opstelling een zeer beperkt aantal vissen reageert op de luchtbellen. Ook dient de opstelling zeer dicht boven de bodem te gaan $(8 \mathrm{~cm})$ om effectief onder snelheid de luchtbellen de bodem te laten raken. De huidige opstelling lijkt nog geen alternatief voor wekkerkettingen of puls te bieden gezien de beperkte effectiviteit waarmee tong en schol gestimuleerd worden om de bodem te verlaten. Verder ontwikkeling en verbetering is noodzakelijk om tot een rendabele visserijmethode te komen. 


\section{$5 \quad$ Kwaliteitsborging}

Wageningen Marine Research beschikt over een ISO 9001:2015 gecertificeerd kwaliteitsmanagementsysteem. Dit certificaat is geldig tot 15 december 2021. De organisatie is gecertificeerd sinds 27 februari 2001. De certificering is uitgevoerd door DNV GL.

Het chemisch laboratorium te IJmuiden beschikt over een NEN-EN-ISO/IEC 17025:2005 accreditatie voor testlaboratoria met nummer L097. Deze accreditatie is geldig tot 1 april 2021 en is voor het eerst verleend op 27 maart 1997; deze accreditatie is verleend door de Raad voor Accreditatie. Het chemisch laboratorium heeft hierdoor aangetoond in staat te zijn op technisch bekwame wijze valide resultaten te leveren en te werken volgens de ISO17025 norm. De scope (L097) met de geaccrediteerde analysemethoden is te vinden op de website van de Raad voor Accreditatie (www.rva.nl).

Op grond van deze accreditatie is het kwaliteitskenmerk $Q$ toegekend aan de resultaten van die componenten die op de scope staan vermeld, mits aan alle kwaliteitseisen is voldaan. Het kwaliteitskenmerk $Q$ staat vermeld in de tabellen met de onderzoeksresultaten. Indien het kwaliteitskenmerk $Q$ niet staat vermeld is de reden hiervan vermeld.

De kwaliteit van de analysemethoden wordt op verschillende manieren gewaarborgd. De juistheid van de analysemethoden wordt regelmatig getoetst door deelname aan ringonderzoeken waaronder die georganiseerd door QUASIMEME. Indien geen ringonderzoek voorhanden is, wordt een tweede lijnscontrole uitgevoerd. Tevens wordt bij iedere meetserie een eerstelijnscontrole uitgevoerd. Naast de lijnscontroles wordende volgende algemene kwaliteitscontroles uitgevoerd:

- Blanco onderzoek.

- Terugvinding (recovery).

- Interne standaard voor borging opwerkmethode.

- Injectie standard.

- Gevoeligheid.

Bovenstaande controles staan beschreven in Wageningen Marine Research werkvoorschrift ISW 2.10.2.105.

Indien gewenst kunnen gegevens met betrekking tot de prestatiekenmerken van de analysemethoden bij het chemisch laboratorium worden opgevraagd.

Indien sprake is van onbeheerste kwaliteit worden passende maatregelen genomen. 


\section{Verantwoording}

Rapport C132/19.

Projectnummer: 4316100161.

Dit rapport is met grote zorgvuldigheid tot stand gekomen. De wetenschappelijke kwaliteit is intern getoetst door een collega-onderzoeker en het betreffende afdelingshoofd van Wageningen Marine Research.

Akkoord:

Ir. E. Schram

Visserij onderzoeker

Handtekening:

Datum:

16 december 2019

Akkoord:

Drs. J. Asjes

Manager Integratie

Handtekening:

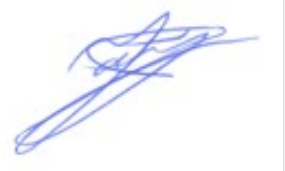

Datum:

16 december 2019 
Wageningen Marine Research

T: $+31(0) 317480900$

E: marine-research@wur.nl

www.wur.nl/marine-research

Bezoekers adres:

- Ankerpark 271781 AG Den Helder

- Korringaweg 7, 4401 NT Yerseke

- Haringkade 1, 1976 CP IJmuiden
Wageningen Marine Research levert met kennis, onafhankelijk wetenschappelijk onderzoek en advies een wezenlijke bijdrage aan een duurzamer, zorgvuldiger beheer, gebruik en bescherming van de natuurlijke rijkdommen in zee-, kust- en zoetwatergebieden.

Wageningen Marine Research is onderdeel van Wageningen University \& Research. Wageningen University \& Research is het samenwerkingsverband tussen Wageningen University en Stichting Wageningen Research en heeft als missie: 'To explore the potential of nature to improve the quality of life' 